\title{
LA ACTIVIDAD DE LA ADMINISTRACION CENTRAL Y DE LAS COMUNIDADES AUTONOMAS
}

\author{
Por \\ E. Casado Iglesias
}

A la memoria de mis padres

\begin{abstract}
SUMARIO: 1. LA ORGANIZACIÓN: CONCEPTO.-2. LOS PRINCIPIOS GENERALES DE LA ORGANIZACIÓN ADMINISTRATIVA. -3. La ACTIVIDAD DE LAS ADMINISTRACIONES EN LA CONSTITUCIÓn: 1) La actividad de la Administración central; 2) La actividad de las Comunidades

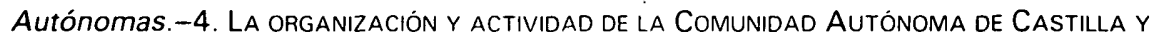
LEón: 1) La organización de la Comunidad: A) Las Cortes; B) El Presidente de la Junta de Castilla y León; C) De los Consejeros y las Consejerías de la Junta. 2) Los principios de actividad de la Comunidad.
\end{abstract}

\section{LA ORGANIZACION: CONCEPTO}

Para García Madarias (1) la organización se refiere a una serie de significados todos ellos relacionados, pero no únicos; por organización se entiende tanto un proceso productivo como una función (el organizador se parece al gestor) como el resultado de ese proceso (entidades públicas o empresas organizadas), se extiende a una actividad bien definida (una Administración pública) como un conjunto de todo lo dicho, con referencia a un ente o institución).

El mismo autor, aceptando la definición de la más común doctrina, la define como uunidades deliberadamente construidas y reconstruidas dotadas de una estructura de redes funcionales dirigidas a la consecución de determinados fines".

En el concepto organización han de distinguirșe esencialmente la concepción norteamericana y la europea al respecto.

Para Wilson Taylor la organización pretende tres objetivos: 1) la racionalización y estructuración de todas las actividades productivas de modo que participan y las adicionales; 2) el control de las organizaciones de trabajo, relación empresa-personal entre todos los servicios de las fábricas, y 3) una progresiva y sistemática separación entre concepción, persecución y ejercicio del trabajo.

(1) Garcia Madarias. J.: Teoria de la organización y sociedad contemporánea, Madrid. 1985, p. 17. 
El homos economicus es el contenido y esencia del taylorismo. Frente a él, y seguidamente, la escuela de las relaciones humanas, iniciada por E. Mayo y nacida hacia el año 1930, tiene como central atención, más que en el aspecto de la estructura formal, en el factor humano; el hombre, contrariamente a Taylor, puede ser estimulado, no por estímulos emocionales. y salariales, sino por recompensas sociales, materiales y no materiales (los «anormales efectos stakarianes»).

Mayo fue seguido por el alemán Kant Leaton y publicadas sus conclusiones en el volumen "The Management and the Worker», en el año 1939, llegándose a las conclusiones de que se olvidaba la cuestión entre el hombre, y se afirma la importancia de los factores generales y sociales en la determinación del comportamiento humano.

Para el mismo autor anteriormente citado (2), la escuela de las relaciones humanas, por lo menos en lo que se refiere a $\mathrm{E}$. Mayo, se limita al mismo ámbito reducido de investigación de la administración científica.

Los experimentos se basaron en unos límites reducidos dentro de la organización específica; si la teoría clásica se limita sólo a la organización formal revelando escasez de variables, ésta está trabajando en un pequeño número de variables, la escuela de las relaciones humanas también se encuentra parcializada, restringiéndose a la organización informal.

Más actual, y vigentemente, está la teoría de las relaciones de las organizaciones, cuyo principal autor es Herbert A. Simon, en su obra "Administrative Behavior», publicada en New York en el año 1947.

Para Simon las organizaciones se desarrollan en actividad. Muy recientemente ha de citarse a Inhernizi (3). Este autor dice textualmente, al respecto: "Las relaciones humanas indican que el trabajador, además de comportarse como homo economicus, tiene relaciones psicológicas que no obedecen a principios económicoracionales», la conclusión es que, teniéndolos en cuenta, su rendimiento en la aplicación del tipo de organización del trabajo, por una parte, y a su satisfacción, por otra, puede mejorar de manera permanente.

La tesis europea de la organización tiene sus orígenes en la teoría clásica de la burocracia, en la obra «La ética protestante y el espíritu del capitalismo», y, fundamentalmente, en "Economía y sociedad", publicada en 1972, y se diferencia de la norteamericana tanto en su concepto empírico como en el metodológico:

(2) Ibidem, id., pp. 104 y ss.

(3) INHERNIZI. E.: Organización y calidad del trabajo de oficina. En el vol. colectivo La automatización y el futuro del trabajo. Madrid, 1988, p. 323. 
El objetivo de esta teoría europea es la burocracia, sobre todo en los concretos aspectos de la administración, como la estatal, así como los partidos políticos y las grandes organizaciones empresariales (4).

Para Max Weber, la burocracia es un tipo de poder, y poder es toda posibilidad de imponer la propia voluntad sobre el comportamiento de otros.

Para el mismo autor citado (Bendis, R.: An intelectual fortait?, New York, 1960), la burocracia tiene como características de tipo histórico o evolutivo:

1) La burocracia es una organización cualificada de trabajo caracterizada por sus escritos.

2) La burocracia es una organización que se basa en la administración.

3) La burocracia en una organización que establece las leyes según el principio jerárquico.

4) La burocracia es una organización que sigue las reglas y las técnicas para el destino del cargo.

5) La burocracia es una organización en lo superior de la sociedad y la autogestión.

6) La burocracia tiende a perseguir que sus recursos estén libres de cualquier tipo de control externo, y

7) La burocracia es un tipo de organización que se ćaracteriza por la proliferación de los participantes.

Con posterioridad, Kalt Manamheim define la burocracia como un tipo de cooperación en el cual la función de cada parte del grupo ha sido efectivamente ordenada $y$ establecida, $y$ donde hay una garantía de sus actividades planeadas y ejecutadas por unos grupos típicos.

Son fines de la organización: una pluralidad de funciones desarticulada entre sí no constituye una organización eficiente. Es de esencia de la organización el mando, es decir, la manera de dirigir $y$ controlar toda la actividad para que se cumplan sus reglamentos, ya que la doctrina clásica definió el principio escalar, o sea, la jerarquía, como la vinculación jerárquica, que representa fundamentalmente la especialización del mando.

Otra nota es la distinción diferenciada de funciones o niveles, a los cuales les viene atribuidas la autoridad para dar órdenes, debiéndose de distinguir, al respecto, el poder y la persuasión.

(4) Para un estudio de la burocracia en nuestra patria, sus origenes y desarrollo posterior, A. DE LA Oliva y GUTIÉRREZ REÑÓn: Sociologia de la Administración Pública Española, Madrid, 1967, y GARCiA MADARIAS, J.: Estructura de la Administración Central (1808-1861), Madrid, 1982 . 
Para el citado autor García Madarias (5) ha de distinguirse entre la organización informal y la organización formal, que es la constituida por la propia estructura organizacional (compuesta de órganos, cargos, relaciones humanas, niveles jerárquicos, etc.), mientras la organización informal es el complejo que se emplea entre los demás elementos humanos de la organización.

La idea de organización administrativa está unida, tanto conceptualmente como en la práctica, al ejercicio del poder, en cuanto que es indispensable que ésta disponga de unos medios para ejercer la dominación sobre la sociedad.

El poder vertebra y pone a su servicio las distintas capacidades humanas, genios y el lenguaje, la transmutación de medios a través de la técnica, la actividad económica y la posibilidad de especulación o transformación, para Baena del Alcázar (6). Sólo entonces, dice el mismo autor, puede decirse que existe verdaderamente la sociedad.

Pero para ello debe disponer de unos recursos económicos, financieros, materiales y establecer su sistema de articulación entre ellos, lo que resulta, tanto para mantener la denominación como para justificar entre los gobernados su presencia y ejercicio, llevando a cabo actividades necesarias o personales a la comunidad.

Coincidentemente con los otros autores, el mismo citado anteriormente afirma que las ideas de organización están unidas, tanto conceptualmente como en la práctica, al ejercicio de poder, en cuanto que es indispensable que éste disponga de unos medios para ejercer su dominación sobre la sociedad.

La disciplina de la Administración pública se refiere a la discusión de los entes públicos, para Caiden (7).

En las organizaciones administrativas, finalmente ha de distinguirse para Baena de Alcázar (8), entre una visión estática y otra dinámica; la visión estática se refiere a su estructura interna y considera, sobre todo, sus elementos.

La visión dinámica afecta, en cambio, a las relaciones entre estos elementos orgánicos y sus posibilidades de actuación, estando formalizada esta visión dinámica en los llamados por la doctrina clásica "principios de organización».

(5) García Madarias. J. M.: Teoría..., citada

(6) BAENA DEL ALCÁZAR, M.: Organización administrativa, Madrid, 1984, p. 14.

(7) GeRALd CAIDEN. E.: Public Administration, Library of Congress, Los Angeles, 1982, y en este mismo sentido de la burocracia en Francia, RIDLEY.T. BLONDEL: Public Administration in France, London, 1980, y para otros paises europeos e hispanoamericanos, SULEIMAN EZA: Bureauts at Policy Marking. New York, 1984

(8) BAena del AlCázAR, M.: Curso de Ciencia de la Administración, v. I, Madrid, 1980. página 19 . 


\section{LOS PRINCIPIOS GENERALES DE LA ORGANIZACION}

Ya en 1971, García-Trevijano (9) decía que es corriente dividir las relaciones interorgánicas en relaciones de coordinación y relaciones de subordinación: que darían lugar al principio de competencia las primeras; y las segundas al de jerarquía, enumerando como principios de la organización bien aquellos que se refieren a las relaciones interorgánicas (competencia, jerarquía y colegialidad) o bien a las relaciones intersubjetivas (descentralización). «No hay principio de coordinación -dice-. Este es un requisito de toda organización, $y$ en el mismo sentido sin coordinación no cabe hablar de organización".

Más actual y vigentemente, Baena del Alcázar (10) indica que la expresión "principios de organización» tiene un valor convencional tanto en la doctrina norteamericana como en la doctrina jurídica europea. Ha de subrayarse, empero, sigue, que pese a que la primera parte de puntos de vista organizativos generales, mientras que en el segundo caso se trata de estudios jurídicos, ambas concepciones no están, ni mucho menos, alejadas unas de otras. Lo sorprendente es que tanto un enfoque como el otro han coincidido en apreciar la existencia de los mismos principios, o al menos de un núcleo común de ellos.

Son los principios de la organización en los clásicos y relaciones de la organización norteamericana las ideas centrales que vertebran la organización administrativa, la cual se monta desde puntos de vista general por la conjunción de todos ellos. En este sentido, dice, la relativa y desacreditada teoría clásica de la organización cita como principios: la competencia, coordinación y control, a los que puede añadirse el de distinción de los órganos entre staff y line, quizás de menor interés del que inicialmente se creyó.

En cambio, la teoría jurídica contempla los principios de organización como un conjunto de reglas de la que se desprenden valiosas consecuencias para los efectos jurídicos de los actos. Estos principios básicos de la organización son los de unidad $y$ jerarquía.

Resumiendo estas ideas, el mismo autor posteriormente señala que «de todas las formas una y otra corriente (la doctrina americana y la europea) coinciden en apreciar la existencia de los principios básicos, que son: la jerarquía, competencia y coordinación, que se refieren a las relaciones orgánicas; y los de centralización, descen-

(9) Garciatrevijano, F.: Tratado de Derecho Administrativo, v. I, Madrid, 1971, p. 390.

(10) BAENA DEL ALCÁZAR. M.: "Administración central y periférica», en vol. col. La Administración en la Constitución, Madrid, 1980, p. 58. 
tralización y autonomía, que afectan a las relaciones que pueden plantearse entre la distintas organizaciones» (11).

Bajo el epígrafe «Dinámica del orden interno», también recientemente, Morell Ocaña (12) indica que las situaciones y relaciones interorgánicas pueden dividirse en dos grupos fundamentales: $1 .^{\circ}$, aquellos que se traban de modo estable entre órganos administrativos, constituyendo la trama de la organización, $y, 2^{\circ}$, las que se establecen en atención a organizaciones administrativas concretas y determinadas, destacando, en tanto se den las mismas, la jerarquía, como más destacada, y la coordinación y la supremacía, que son del grupo primero.

En lo que respecta al segundo tipo de relaciones han de citarse: la delegación, la evocación y la sustitución.

\section{a) La jerarquia administrativa}

La jerarquía, en su concepto actual, es proveniente del resultado de la refundición del punto de vista de distintas épocas. De una parte está latente en ella la supremacía regia de la Administración del Antiguo Régimen, acogiendo en realidad a unos agentes subordinados unos a otros; de otro lado se han tomado elementos de la distinción territorial del poder que la Iglesia Católica había heredado, en la Edad Media, del antiguo régimen romano, dice Baena del Alcázar (13).

Más próximamente, para el mismo autor (14), la jerarquía consiste en la vertebración de las organizaciones mediante la distribución de órganos en escalones sucesivos subordinados unos a otros, existiendo en dichas organizaciones unas relaciones despersonalizadas que se basan en la delegación a los titulares de los órganos.

No hace falta indicar que la subordinación implicará una distinción entre fines que ejercen y expresan su voluntad de poder $y$ quienes realizan las tareas materiales de ejecución.

La jerarquía implica, así, actualmente, cuando menos: $1 .^{\circ}$, la existencia de unos órganos complejos, ya que sólo en el seno de éstos pueden darse relaciones entre los titulares de los diversos órganos menores; $2 .{ }^{\circ}$, la distinción de tipos de tareas según los distintos órganos menores; $3 .^{\circ}$, la distinción de tipos de tareas según los distintos escalones jerárquicos, cuestión intimamente relacionada con la competencia; $4 .{ }^{\circ}$, el distinto valor jurídico que se

(11) Ibidem, Curso..., citado, p. 73

(12) MORELl OCAÑA, L.: Derecho Administrativo, v. Il, Madrid, 1987. pp. 26-27.

(13) BAENA DEL ALCÁZAR, M.: Curso..., cit., p. 73, y Administración central..., cit., p. 68.

(14) Baena del AlCÁzAR, M.: Curso..., cit., p. 77. 
otorga a los actos de los órganos situados en los diferentes escalones jerárquicos $y, 5 .^{\circ}$, finalmente, la doble corriente de información que suminstran los órganos inferiores a los superiores $y$ de instrucciones y criterios de actuación que proporcionan los superiores a los subordinados.

\section{b) La competencia}

La competencia es un conjunto de facultades, de poderes y de atribuciones que corresponden a un determinado órgano en relación con los demás.

Consiste en la vertebración de las organizaciones mediante la distribución de los órganos en escalas sucesivas, subordinadas unas a otras, existiendo en dicha organización unas relaciones despersonalizadas que se basan en la obediencia de los titulares a los órganos, de acuerdo con unas normas reglamentarias.

La medida de competencia se reserva para la actuación de los órganos como detenimiento de ese total organismo administrativo.

Este tipo de distribución suele referirse al valor de los actos y de las directrices de actuación, independientemente de la materia sobre la que verse la actividad de los órganos.

La competencia funcional expresa, en cambio, la repartición o asignación de tareas por razón de la materia y se refiere a grandes sectores de la organización en proporción con el temario de ésta. Dichos grandes sectores, a su vez, resultan ordenados según los sistemas jerárquicos y funcional.

La competencia territorial, finalmente, se refiere al ámbito territorial en el que pueden actuar válidamente los órganos de la administración considerada.

El uso de esas competencias es un bien; a la inversa, se habla así de incompetencia jerárquica o incompetencia funcional (incompetencia territorial de los órganos).

Con el título de "Alteraciones de la competencia», Baena del Alcázar (15) indica que dentro de estas actuaciones están como más destacadas la delegación y la desconcentración, mientras que pueden considerarse figuras menores la sustitución y la avocación por su carácter excepcional, y la suplencia por su escasa entidad para el funcionamiento orgánico.

La delegación consiste en el traspaso temporal de atribuciones de una persona física a otra, entendiéndose que se trata de titulares de órganos de la misma organización.

La delegación tiene carácter personal y temporal, lo que lleva a la consecuencia de que, cuando cambia la persona que está al

(15) BAena del AlCÁzar, M.: Curso..., cit., p. 74. 
frente de los órganos, el acto deja de ser válido. La delegación no puede delegarse a su vez, "delegata potestas non delegatur». Los actos dictados por delegación, a los efectos jurídicos, se entienden dictados por el titular del órgano delegante, ya que dicho órgano no pierde la competencia.

Concepto distinto es el de la desconcentración, que supone, por el contrario, el traspaso de competencias de un órgano a otro en el seno de una organización compleja.

También la desconcentración, a diferencia de la delegación, no es un traspaso personal ni temporal; sino que es necesario que se dicte una regla general.

La finalidad principal de la desconcentración, sigue el mismo autor (16) consiste en acercar el centro de decisión al entorno afectado por la misma. "Se comprende así que, apurando la finalidad del concepto, ha de distinguirse entre desconcentración central, a favor de los órganos inferiores de la organización central, y la desconcentración periférica, a favor de los órganos de este carácter; como así mismo entre desconcentración estática y dinámica».

La avocación consiste en la posibilidad de que el superior llame a sí las competencias de los inferiores; es decir, que en un momento determinado se altere el orden de las competencias, por adoptar el titular de un órgano superior decisiones que competían al de uno inferior $(16, \mathrm{~B})$.

Para Morell Ocaña (17), la avocación es el acto en cuya virtud un órgano, previamente habilitado para ello por ley, hace suya una competencia originariamente atribuida a otro órgano.

Similarmente al anterior autor, para Baena del Alcázar (18), la avocación es el inverso de la delegación; la suplencia, sin embargo, se refiere a un asunto concreto y determinado. Tiene por objeto la generalización de actuaciones. Ello sucede en los casos de vacante, ausencia o enfermedad.

La figura se aplica, por tanto, no sólo cuando la causa se ha producido de pleno derecho, sino también cuando el titular del órgano está imposibilitado para realizar su trabajo cotidiano.

\section{c) La coordinación}

La coordinación consiste en la tarea de evitar superposiciones y fricciones de las competencias de los órganos situados en una

(16) BAENA DEL AlCAZZAR, M.: Id., p. 75.

(16. B) Ibidem, id., p. 75.

(17) MORELl OCAÑA, L.: Derecho..., cit., id, p. 34.

(18) BAENA Del AlCÁZAR, M.: Curso..., cit., p. 75. 
misma escala jerárquica, lo que lleva a un planteamiento estático y otro dinámico.

Según el planteamiento estático hay que efectuar una distribución de tareas entre los órganos, que haga posible un funcionamiento meramente racional y eficaz.

Según el planteamiento dinámico hay que realizar una tarea que trate de solucionar los conflictos y acomodar las actuaciones de los órganos.

La coordinación, para el citado autor Baena del Alcázar (19) es un problema de poder, pero, como en otros casos relativos a la práctica de los principios de organización, el tema se entiende mejor desde un prisma negativo, es decir, en los casos en que no se produce la coordinación. Es frecuente entonces que se tome alguna medida que, si no es acertada, suele desplazar la autoridad fuera de la organización, bien creando una Comisión, bien confiando el problema a un tercero que carece de poder efectivo.

La coordinación, dice Morrell Ocaña (20), que también la incluye como principio de la organización, es el supuesto en que los intereses de que son portadores los entes tienen un carácter complementario, desde el punto de vista de su consecución, de suerte que una actuación conjunta o coordinada puede imponer un ahorro de medios o una mejor consecución de los fines de cada uno.

\section{d) El control}

Si bien no admitido uniformemente como principio general de la organización administrativa en la Constitución, hemos de hacer referencia al control.

El control viene a concretarse, para Baena del Alcázar (21), en la necesidad de asegurar que se cumplan las finalidades de la organización de modo correcto. El control está ligado a la jerarquía, en cuanto que los superiores son responsables del buen y correcto funcionamiento de las organizaciones.

En este sentido es lícito plantearse los problemas de la capacidad de control, cual hace la doctrina norteamericana al plantearse al ámbito orgánico que puede desarrollar eficazmente una persona. Lo acaecido es, sin embargo, dice el mismo autor, que suele encomendarse a órganos especializados por razón de la competencia que asegure una actuación correcta en una materia determinada,

(19) Baena del AlCÁzaR, M.: Curso..., cit., p. 76.

(20) MORELL OCAÑA, L.: "Las entidades locales, elemeritos integrantes de la organización territorial del Estado y de las Comunidades Autónomas», en Civitas núm. 85, julio-septiembre. 1987, p. 347.

(21) BAEnA del AlCÁzar, M.: Curso..., cit., p. 76. 
como por ejemplo la financiera. Si se aplica, en cambio, el control con un sentido más amplio, se está hablando ya de una realidad distinta; más próxima a la visión o exigencia de especialidades, y ajena a las cuestiones estructuralmente orgánicas.

Punto de vista, sin embargo, distinto al expuesto, es el de Morell Ocaña (22), que también lo incluye como principio de la organización incluido en el Texto constitucioal. Para este autor, el control hace referencia a las relaciones de supremacía de unos intereses frente a los demás. "Se producen estas relaciones -dice textualmente- cuando los intereses de unos entes determinados pueden quedar afectados o condicionados por la actuación de otro que está situado en una posición inferior en atención a los intereses de que es portador. Son, en definitiva, relaciones que proporcionan una apreciación de uno o varios intereses públicos determinados, de los que es portador el ente superior».

Las relaciones de control, sigue, se diferencian por su objeto, distinguiéndose los controles de legalidad o de oportunidad; y desde otro punto de vista, pueden referirse al control de la organización, su estructura y su gasto; o a la actividad de la misma.

En resumen, para el referido autor, el control ues el conjunto de relaciones que proporcionan una primacía a uno o varios intereses públicos determinados, de los que es portador el ente superior».

\section{e) La centralización y la descentralización administrativas}

Si bien estos principios, comúnmente, se consideran o estudian por separado, por nuestra parte lo hacemos conjuntamente dada su íntima relación, expresada en la antítesis centralización-descentralización.

La centralización significa que todas las decisiones importantes se adoptan en el ámbito básico de la organización, bien por inexistencia de otras unidades menores, bien por tener éstas muy escasas posibilidades de actuación.

En la medida que se encuentre centralizado, el funcionamiento orgánico depende, en definitiva, de lo que haya establecido al respecto la Constitución, refiriéndose a ella como documento base, que expresa la voluntad política por la que han de regirse las organizaciones públicas.

La descentralización consiste en el traspaso de competencias decisorias a las demás personas jurídicas inferiores, decía ya en 1971 García-Trevijano (23).

(22) MORELl OcAÑA, L.: Derecho..., cit., id, p. 28, y Las entidades..., citada, id.

(23) GarciatreviJano, F.: Tratado de Derecho administrativo, t. 1. v. II, Madrid, 1971. página 282. 
Más recientemente, para Baena del Alcázar (24), se ha producido en España una evolución de la doctrina, a propósito de la idea de la descentralización, que ha ido poniendo énfasis en distintos aspectos del problema.

Si bien en un primer planteamiento, que se produce al iniciarse la renovación del Derecho Administrativo español, la óptica que prima es la de considerar a la descentralización como la existencia de una constelación de personas jurídicas, poniéndose el acento sobre el hecho de que la existencia de entes distintos es condición previa para el planteamiento del tema; otra tendencia ha visto, en cambio, la descentralización como el sistema de articulación de organizaciones públicas, montado para el cumplimiento de las funciones estatales, punto de vista en el que se apunta ya el aspecto dinámico del problema.

Durante los últimos años del anterior régimen de Franco, la doctrina ha sido más exigente, para el mismo anterior autor, en cuanto a los requisitos necesarios para que existiera una auténtica descentralización, por desconfianza hacia las operaciones políticas manipuladoras que intentaban presentar como descentralización lo que no era más que delegaciones o bien disposiciones descentralizadoras.

A finales de la década 1940-1950, señala posteriormente Baena del Alcázar (25), se pensaba que existía descentralización por el solo hecho de que hubiera más de una persona jurídica con su organización correspondiente. Después, en un paso decisivo al respecto, se puso especial énfasis en el requisito de que se diera traspaso de posibilidades de actuación. Pero años más tarde la doctrina continuó exigiendo otras características, sobre todo el que la organización menor tomara las decisiones en nombre propio, y el que el Estado no ejerciera el control de oportunidad.

La descentralización no se refiere a las atribuciones ni a la competencia, sino a los fines a cumplir, puesto que estos fines se atienden en el estudio de la organización cuando se habla de funciones. Por otra parte, los sujetos entre quienes se opera no son personas físicas ni órganos (a diferencia de la delegación y la desconcentración) sino organizaciones administrativas, que desde el punto de vista del Derecho tienen personalidad jurídica propia.

En resumen, para el autor de referencia (26) y para la doctrina española reciente, se define la descentralización como el traslado de funciones desde un ente administrativo (normalmente el Estado) a otros entes administrativos menores, siempre que ello no

(24) BAENA DEL AlCÁZAR, M.: Administración Central..., cit., p. 61

(25) Ibidem, Curso..., cit., p. 77.

(26) Ibidem, Administración Central..., cit., p. 63. 
implique la efectiva transferencia de poderes decisorios ejercidos en nombre propio o por la entidad a cuyo favor se hace la descentralización.

Según la organización beneficiaria de la descentralización ésta se clasifica territorial o funcionalmente.

La descentralización territorial es la que se realiza en favor de las entidades locales y de aquellas otras que administran los intereses de la población de un territorio más amplio que el de la provincia, o un municipio en su caso.

Cuando se efectúa se está tomando una decisión importante al asignar funciones a entes que constituyen una prolongación del Estado, permitiéndoles que actúen como centro de decisiones políticas o administrativas propias, en mayor medida de lo que venían haciéndolo hasta el momento de la descentralización.

La descentralización funcional es la que se efectúa a favor de las organizaciones que constituyen una prolongación funcional del núcleo de las Administraciones públicas, en su mismo territorio. En este caso, la descentralización es simplemente una operación técnica que no coincide con el uso vulgar del vocablo. Existe, desde este punto, la descentralización, porque se traspasan funciones desde el Estado a sus organizaciones, creadas para cumplir fines específicos.

Pero como estas organizaciones no son cosa distinta del Estado mismo, se está efectuando una corrupción del lenguaje, ya que a veces la operación técnica significa que el Estado asume tareas que antes no realizaba; es la llamada también descentralización por servicios.

Recientemente la noción ha sido desbordada en la realidad para referirla a toda organización especializada por su fin o creada por ella, y desgajada de la general (normalmente la del Estado).

La doctrina jurídica, de acuerdo con el mismo autor, maneja como complemento del concepto de descentralización el concepto de tutela, que se considera como el conjunto de poderes que conserva la organización mayor (normalmente el Estado) sobre los entes descentralizados.

La tutela, como una forma de controlar los entes territoriales, consiste en la existencia de poderes de la organización central sobre los entes descentralizados, poderes que pueden ser de muy distinta naturaleza.

Es cuestión fundamental a propósito de la descentralización un presupuesto político. En efecto, el dato básico para que se lleve a cabo la descentralización es la existencia de un Estado centralizado. Sólo entonces, cabe, mediante una voluntad política y tomada por 
ley o reglamento, efectuar el traspaso de funciones en que consiste la descentralización.

\section{f) La autonomía}

La autonomía, para Baena del Alcázar (27), es una idea completamente distinta de la descentralización. Supone que las organizaciones menores tienen la posibilidad de cumplir unas funciones determinadas por derecho propio en virtud de los principios inspiradores del sistema político (normalmente en la Constitución) y no en virtud de una decisión política concreta del Estado central sobre la que normalmente los beneficiarios de la descentralización no han sido consultados.

La autonomía significa la posibilidad de darse poderes propios distintos de los que acoge la organización general. La diferencia entre autonomía política y la administrativa se refiere principalmente al tipo de normas. Cuando se trata de una autonomía política las organizaciones menores pueden darse leyes a sí mismas, a diferencia de la autonomía administrativa en la que sólo pueden aprobarse Reglamentos por los mismos. Se comprende que sólo en este caso los reglamentos no pueden infringir las leyes de la organización general, mientras que sucede lo contrario en el caso de la autonomía política.

Además de la administración dé la actividad desarrollada, la autonomía debe implicar la posibilidad de imponer una organización propia, y también, aunque sea de modo restringido, la de llevar a cabo una actuación financiera distinta de la estatal.

Finalmente, ha de tenerse en cuenta que la autonomía no impone una desorientación completa de la organización general. El ente autonómico sigue siendo una parte de esa totalidad orgánica en que consiste el Estado; en otro caso se estaría ante un Estado diferente.

\section{LA ACTIVIDAD DE LAS ADMINISTRACIONES EN LA CONSTITUCION}

\section{La actividad de la Administración Central}

Frente al principio de «unidad de poder y coordinación», dice Garrido Falla (28), proclamado enfáticamente por el artículo 2. ${ }^{\circ}$, párrafo II, de la derogada Ley Orgánica del Estado, es obvio que nuestra Constitución se basa en el principio de la división de

(27) Baena del AlCÁzAR, M.: Curso..., cit., p. 79.

(28) GARRIDO FALLA: «La función constitucional de la Administración pública», en vol. col. citado La Administración en la Constitución, pp. 11-12. 
poderes. Paradójicamente, sin embargo, los tres clásicos poderes (ejecutivo, legislativo y judicial) no se enumeran (29), ni siquiera con la excepción del poder judicial, ni se nombran con tal terminología.

De la comparación de los artículos 92 y 103 de la Constitución, sigue el mismo autor, debemos dejar establecidas ciertas condiciones, cuya única problemática no puede olvidarse:

a) La primera sería que el Gobierno y la Administración son cosas diferentes. Desde otro punto de vista, objetivo u orgánico, esta impresión se corrobora si tenemos en cuenta que el artículo 97 establece la composición del Gobierno, y por su parte, el artículo 103, II, remite a la Ley de Composición de los Organos de la Constitución.

b) Una segunda conclusión sería que el Gobierno dirige, y que, por tanto, la Administración obedece. O sea, y vista ahora la cuestión desde un punto de vista objetivo de la naturaleza de la función desarrollada, el Gobierno desarrolla una actividad política o principal y la Administración una actividad administrativa o subordinada.

c) En tercer lugar, de acuerdo con el artículo 97, el Gobierno dirige la función ejecutiva, lo cual parece postular que el Gobierno es el Poder Ejecutivo, y

d) En cuarto lugar, según el artículo 97, el Gobierno ejerce la potestad reglamentaria.

Pero frente a esto ha de afirmarse, para el mismo anterior autor, la Administración (tanto subjetiva como objetivamente) actúa con fuerza propia directamente subordinada a la Ley y al Derecho, de acuerdo con el mismo artículo 103 de la Constitución.

Y ello es verdad porque la Administración pública tiene carácter institucional, en el sentido que el institucionalismo tiene en el Derecho público a partir del concurso.

¿Qué es una institución?, se pregunta el mismo autor. Una institución no es una persona jurídica. Las notas que caracterizan una institución son fundamentalmente:

1) Que la institución realiza en su actuación una agrupación de los fines que persigue.

Cuando se habla de la Administración como «instrumento» se está negando entonces su concepción institucional. La Administración como «aparato» significa que la Administración es instrumental con respecto a la actuación política previamente fijada, y consiguientemente la Administración es medial en cuanto al cumpli-

(29) Contrariamente, BAENA DEL ALCÁZAR, M.: Curso..., cit., p. 195. 
miento de estos fines. Cuando una Administración, en cambio, asume como propios los fines que persigue, entonces estamos precisamente institucionalizando la Administración.

Como se desprende del párrafo primero del artículo 103 de la Constitución, esos fines son «los intereses generales». La delicada operación de los fines de este artículo de los intereses del Estado (el bien común), y atribuyéndolos como propios a la Administración estática (institucionalización).

2) La segunda nota es que la institución actúa en su forma propia y es además esos fines, con lo que se consigue nada menos que el superar la ciencia del Gobierno.

El dato de cómo los fines del Gobierno en los países evolucionados no perjudican la marcha de la Administración y el funcionamiento de los servicios públicos constituye la prueba definitiva de una Administración institucionalizada.

3) La institución se regula por las normas propias del comportamiento, que es una cosa distinta a decir que la institución está sometida a Derecho.

Baena del Alcázar (30), un tanto similarmente al criterio del autor citado primeramente, indica que «es indudable que el Estado español previsto por la Constitución difiere en muchos puntos del que conociamos hasta ahora, transformado a través de la reforma y no de la culturan. Y adelantándose a la realidad vigente, afirma seguidamente que es indispensable, por tanto, llevar a cabo una labor de adaptación de las estructuras orgánicas estatales al nuevo texto constitucional y a la realidad política que ha precedido al mismo, y que resulta indispensable, por tanto, llevar a cabo una labor de adaptación de las estructuras orgánicas tradicionales a la realidad jurídica que ha precedido al mismo y que resulta ahora ordenada por él en sus líneas maestras y básicas.

Esta reforma no se limita, por supuesto, a la Administración pública; debe abarcar, desde luego, las distintas zonas del Estado, como por otra parte prevé el propio texto constitucional.

La estructura orgánica a la que hace referencia el anterior autor es efectivamente mucho más extensa de la que a primera vista se pudiera pensar y que no sólo abarca el conjunto de los Ministerios articulados bajo la dependencia del Gobierno, sino además los órganos periféricos, la organización administrativa en el exterior, los organismos autónomos y las empresas públicas, sin olvidar a la Administración militar; a pesar de ser una Administración cualificada, no por ello deja de ser una Administración pública.

(30) BaEnA del AlCÄZAR, M.: Administración Central..., cit., p. 49. 
Más recientemente, el mismo autor, afirma que se ha difundido la idea, sobre todo en los puestos de trabajo, de que la Constitución promulgada trata escasamente de la Administración pública, basándose en la idea de los escasos artículos que se dedican a la Administración del Estado, y fundamentándola, sin duda, en que no era mucho lo que se modificaba, sobre todo referido al Derecho Administrativo español.

El Estado anterior era de carácter totalitario, por lo que inicialmente dominaba a la sociedad, e incluso en un momento posterior, cuando ya se había abandonado esta pretensión, no por ello se implicaba que todos los intereses colectivos fueran gestionados por el mismo Estado o por las entidades concertadas de alguna manera con él.

La Administración, en consecuencia, respondía a ese concepto monolítico y se asentaba en un control. Toda la Administración lo era del Estado, como se definía mucho de los juicios doctrinales, que distinguían entre Administración directa del Estado e indirecta.

El Estado actual parte de una Constitución claramente pluralista y se manifiesta, en cuanto a la sociedad y al Estado mismo. Por lo que se refiere a la sociedad los intereses colectivos han de sistematizarse por el Estado.

En la Constitución vigente no existe un sólo centro de poder, sino una multiplicidad de centros, cada uno de los cuales tiene una propia Administración pública. El sistema es complejo, como lo era también la Administración del régimen anterior, pero se trata de una complejidad organizada de modo diferente.

Para el mejor estudio del artículo 103.1 de la Constitución, según el cuial «la Administración pública sirve con objetividad los intereses geñerales $y$ actúa de acuerdo con los principios de eficacia, jerarquía, descentralización y coordinación, con sometimiento pleno a la Ley y al Derecho», conviene hacer la distinción, siguiendo en este apartado al autor citado anteriormente (31), entre Estado-organización y Estado-comunidad.

El primero se reduce al aparato central que constituye el núcleo duro del Estado. El segundo comprende a todas las entidades que satisfacen necesidades colectivas y se caracterizan como públicas.

El núcleo duro comprende todas las organizaciones competentes en la integridad del territorio nacional, incluyendo las organizaciones administrativas propias de la Corona, el Tribunal Constitucional, las Cámaras (con sus organizaciones dependientes, como el Tribunal de Cuentas y el Defensor del Pueblo), el Consejo General del Poder Judicial, y finalmente, el Gobierno y la Administración.

(31) Baena del AlCÁzar, M.: Curso..., cit., pp. 194 y ss. 
El Estado-comunidad comprende, además de todos los elementos del Estado-organización, las Comunidades Autónomas, las entidades locales y aquellas otras organizaciones calificadas como públicas y que forman parte del referido medio duro doctrinal.

Dentro del Estado-organización, y a nuestros efectos, se ha de considerar la Administración dependiente del Estado y las demás organizaciones administrativas.

La Constitución española parte del esquema de la división de poderes, ya que dicha distinción sólo utiliza la expresión "poder» para referirse al poder judicial (arts. 117 y ss.). mientras que respecto a otras organizaciones se habla de potestad, lo que significa atender a un concepto bien distinto. Lo que hay es una pluralidad de organizaciones que realizan diversas tareas, y ello dentro del mismo Estado nuclear o Estado-organización. Son altos órganos constitucionales en nuestro sistema la Corona, el Tribunal Constitucional, las Cámaras Legislativas, la Justicia y el complejo Gobierno-Administración.

Cada uno de estos altos órganos constitucionales necesita disponer de una organización administrativa propia, con objeto de articular los medios personales, materiales y financieros indispensables para el cumplimiento de los fines especificados por la Constitución. Son Administraciones mediales que han de tenerse en cuenta y presentes en problemas peculiares.

Estas Administraciones mediales tienen una entidad mínima (salvo el caso de la Justicia), ofreciendo un interés menor a efectos de la contemplación general de los problemas administrativos.

La Constitución de 1978 regula en su título IV el «Gobierno y la Administración», refiriéndose, sin duda, al Gobierno y la Administración del Estado Central o Estado-organización. No significa ello, empero, que deba o pueda confundirse el Gobierno con la Administración.

En el régimen anterior, de acuerdo con la Ley de Régimen Jurídico del Estado de 1957, se daba una auténtica confusión, ya que incluía entre los altos órganos de éste al Consejo de ministros y al presidente del Gobierno. Actualmente ha de mantenerse la diferencia entre el Gobierno y la Administración. De una parte, es bien significativa la denominación del título IV «del Gobierno y la Administración»; de otra parte, la sistemática constitucional es bien significativa. Así, en efecto, regula al Gobierno en los artículos 97 al 102, mientras que se dedica a la Administración en los artículos 103 a 107.

Según el artículo 97 citado «el Gobierno dirige la Administración civil y militar», lo que significa que hay un Gobierno dirigente distinto de la Administración dirigida. De acuerdo con el artículo 
98.1, el Gobierno se compone del presidente y los vicepresidentes, los ministros y los demás miembros que establezca la Ley. La Administración está, en cambio, constituida por la organización subordinada, siendo nexo de unión entre ambas los ministros titulares de los Departamentos ministeriales.

No existe en el texto constitucional una definición de lo que se entiende por Administración, ni siquiera un mandato relativo a su constitución. Sin embargo, el párrafo 2 del artículo 103 del texto constitucional alude a la Administración destacando la realidad primaria de la misma, al disponer que sus órganos son creados, regidos y coordinados de acuerdo con la Ley.

Los constituyentes han visto, por tanto, a la Administración como un colectivo formado por órganos, como una organización que, subordinada al Gobierno, sirve los intereses generales.

Nada impide, desde luego, que se prediquen otros atributos de la Administración pública, como pueden ser su personalidad jurídica, su integración por el personal funcionario o los intereses económicos y financieros que tienen confiados; desde el punto de vista constitucional hay que ver a la Administración como un complejo de órganos debidamente coordinados.

Este agregado orgánico, contrariamente de lo que se ha afirmado en anteriores ocasiones, tiene una considerable utilidad, tanto por el volumen que representa en España y en otros países y Estados modernos, como por considerar frecuentemente los intereses generales en su conjunto en vez de atender a fines especiales y concretos.

La Administración es, en definitiva, «una organización dependiente del Gobierno, que debe actuar de acuerdo con la Ley y que satisface los intereses generales de toda la Comunidad». Los intereses generales mencionados en el artículo 103 no pueden considerarse desconectados del todo del título I, relativo a los derechos y libertades de todos los españoles.

Las Cortes aprobarán las leyes reguladoras, el Gobierno dará el impulso político y la política se encargará de asegurar los derechos cuando discutan ante los tribunales.

En relación a la regulación de la Administración pública como una organización subordinada al Gobierno, la Constitución se refiere someramente al procedimiento $y$ a los actos administrativos, $y$ establece el principio de control de la actuación administrativa por los Tribunales de Justicia.

De otra parte se refiere en el artículo 107 al Consejo de Estado como máximo órgano administrativo de carácter consultivo.

Pero, en relación a nuestro tema, en el artículo 103 no sólo se ofrece una concepción de la Administración pública en su párrafo 
2, al decir que «los órganos de la Administración del Estado son creados, regidos y coordinados de acuerdo con la Ley», sino que además se contemplan conjuntamente los órganos administrativos y los funcionarios que son titulares de los mismos, o que se integren en ellos.

Los principios genéricos a que debe atenerse la Administración se encuentran en el importante párrafo 1) del mencionado artículo 103. El estudio de este precepto fundamental, de acuerdo con el mismo autor, resulta más complejo de lo que pueda pensarse a primera vista, y quizá de lo que se pensó estando muy reciente el texto constitucional.

En el referido párrafo 1) del artículo 103 se regulan diversas materias, como son el fin de la Administración pública, los criterios de actuación, los principios de organización $y$, por último, el principio jurídico fundamental de sometimiento a la Ley $y$ al Derecho.

El fin de la Administración pública es el servicio de los intereses generales, que junta la doble característica del carácter subordinado de la actuación y de la universalidad de sus fines. La Administración, además de esa dependencia del Gobierno, ha de ser dirigida por éste, y por ese mismo hecho la Administración no existe por sí misma, no cumple unos fines que sean exclusivamente propios; es una instancia subordinada que no puede existir sino en función de los intereses y necesidades de toda la colectividad.

Son sistemas de actuación de esa Administración, de acuerdo con el párrafo 1) del artículo 103: $\left.1 .^{\circ}\right)$ El carácter objetivo de actuación de la misma, al decirse muy expresamente que el servicio de los intereses generales ha de hacerse con objetividad. La idea puede interpretarse, de primero y directo, en el sentido que la Administración, compuesta por personas profesionales, según se desprende del párrafo 3) del mismo artículo 103, debe ser neutral y actuar con imparcialidad política; es decir, la Administración pública no debe dejarse llevar por criterios partidistas. Pero junto a esto la objetividad tiene facetas más amplias que deben relacionarse con la profesionalidad de los administradores. Hay que servir los intereses generales sin atender a preferencias personales de cualquier índole, sin establecer distinción alguna entre los ciudadanos o los grupos, y ateniéndose a una racionalidad que tenga en cuenta los hechos objetivos, las necesidades sociales y la línea política que se haya establecido para solucionarlas; $2 .^{\circ}$ ) La eficacia. La Constitución enumera esta eficacia como si fuera un principio. pero está claro que la idea tiene un significado distinto de los que adoptan los demás principios mencionados que aluden al funcionamiento de la organización. La idea alude al resultado de la gestión 
administrativa y no a la estructura del complejo orgánico en que consiste la Administración.

Es quizá, más que un principio que plantea una cuestión de principios. La Administración no existe por sí misma y para sí misma; debe servir los intereses generales, y debe hacerlo determinando sus resultados concretos, que responden de algún modo a la adecuación entre los medios de que se dispone y los fines que se pretende cumplir.

Son, empero, principios de la organización que la Constitución menciona: La jerarquía, la descentralización y la coordinación. Todas estas nociones, que no son principios de la organización en sentido técnico (la desconcentración no es un principio, sino, como se ha expuesto con anterioridad, es una alteración de la competencia) no tienen por qué aplicarse simultáneamente y a las mismas realidades orgánicas.

Contra determinadas críticas hechas por la doctrina, no se consideran en este precepto constitucional ideas contradictorias (no se puede, en efecto, desconcentrar y concentrar al mismo tiempo), pues nada se opone a que estas ideas o principios se apliquen a realidades distintas.

La descentralización a que se refiere el precepto puede parecer en principio desorientador, pues la ordenación territorial del Estado, para la Constitución, se inspira en la idea clásica de la autonomía, muy distinta de la descentralización territorial. Esta última existe y se asume en el texto constitucional, que desempeña, sin duda, un papel menor y subordinado.

Descartada la descentralización territorial, puede interpretarse que se está admitiendo la descentralización funcional, con lo que por la vía del artículo 103 resultaría admitida la pluralidad y diversidad de los órganos autónomos que no han sido contemplados de forma directa por la Constitución.

Al no especificar el texto del citado artículo 103, cual es la descentralización a que se refiere, ha de entenderse en el sentido anteriormente expuesto.

Los demás principios recogidos en ese texto han de referirse a la Administración central del Estado. La jerarquía no supone gran novedad con las ideas que se han expuesto en páginas anteriores, puesto que se limita a consagrar la existencia de una organización regida por órganos con criterios de subordinación impersonales que son propios de nuestro desarrollo económico y cultural.

La jerarquía es una de las notas típicas de la Administración pública en sentido weberiano. Pero la Constitución lo que dicta es que todas las competencias correspondan a los órganos de manera jerárquica, pues este es el significado que debe darse a la 
descentralización. La jerarquía de este párrafo primero del actual artículo 103 nos está también indicando que se admiten en el sistema competencial los órganos periféricos del Estado que actúan en las decisiones territoriales que afectan a las divisiones territoriales del mismo.

La descentralización administrativa está apoyada en la esfera de los principios que se contienen en los artículos 141, sobre la provincia como ente territorial («La provincia -dice el mismo- ... es una división territorial para el cumplimiento de las actividades del Estado»), y el 154, sobre el delegado del Gobierno en las Comunidades Autónomas.

Finalmente, la referencia a la coordinación está indicando la voluntad política de que funcionen armónicamente los distintos conjuntos orgánicos.

Es decir, mediante ella se está aludiendo a que los diferentes órganos administrativos deben de actuar de modo que los roces de competencia no estorben el cumplimiento de estas tareas que tienen encomendadas.

Nada impide para ello, por otro lado, y por la mención del párrafo $2 .^{\circ}$ del artículo 103 , poner esta idea en relación con la anterior de la administración de los organismos autónomos por la vía de la descentralización funcional. Por consecuencia, el funcionamiento autónomo del párrafo primero del artículo 103 por la vía de la descentralización funcional. En consecuencia, el funcionamiento armónico debe predicarse también de las relaciones que existan en los organismos autónomos, entre unos y otros, $y$ en los órganos que integran la organización centralizada.

Finalmente, también es de interés el principio que se consagra conforme a la idea del Estado de Derecho, y es la de que la Administración actúa con sometimiento pleno a la Ley y al Derecho. Se concreta de esta forma, en el caso de la Administración, lo dispuesto en el artículo 91, a cuyo tenor los poderes del Estado se encuentran sometidos a la Constitución y al resto del ordenamiento jurídico.

La Administración es, pues, para la Constitución, un conjunto orgánico jerarquizado eficaz y armónicamente cumpliendo con objetividad los intereses generales de sus órganos territoriales y periféricos y sus organismos autónomos. Dicho conjunto, dirigido por el Gobierno, debe actuar con objetividad y eficacia, y está sometido a la Ley y al Derecho, lo que se consigue por medio de los Tribunales de Justicia.

¿Y qué sucede, finalmente, con el principio de control? El principio de control no ha sido considerado por la Constitución, 
hecho criticado por parte de la doctrina (32). No así para Morell Ocaña, que indica, la Constitución sí proporciona también un fundamento a las relaciones de control en cuanto protege unos intereses públicos en relación con otros (33).

Para Baena del Alcázar (34) el principio de control es, efectivamente, un principio de importancia. Siendo deseable que se hubiera destacado en el texto constitucional, pues en su sentido más amplio, el control se identifica con la revisión o exigencia de responsabilidades.

\section{La actividad de las Comunidades Autónomas}

Junto al Estado-organización hay que considerar además los elementos del Estado-organización que forman parte de la organización territorial. De acuerdo con el artículo 137 de la Constitución, los Municipios, las Provincias y las Comunidades Autónomas "gozan de autonomía para el cumplimiento de sus referidos fines».

¿Es aplicable a las Comunidades Autónomas el párrafo $1 .^{\circ} \mathrm{del}$ artículo 103 constitucional según el cual «la Administración pública sirve con objetividad los intereses generales y actúa de acuerdo con los principios de eficacia, jerarquía, descentralización y coordinación»?

Para la solución de este interrogante es fundamental el estudio del párrafo $1 .^{\circ}$ del artículo 149 constitucional, según el cual el Estado tiene competencias sobre "Las bases del régimen jurídico de las Administraciones públicas y el Régimen estatutario de sus funcionarios, que, en todo caso, garantizará a sus administrados un tratamiento común ante ellas».

El último párrafo e inciso del artículo mencionado indica que al dictarse esas normas comunes que se aplican a la propia Administración Central será necesario recoger en ellas los mandatos, principios y criterios del artículo 103, por lo cual dichos principios de actividad deben aplicarse a todos los ámbitos administrativos.

El Estado ha de dictar, de acuerdo con el artículo mencionado, la legislación general básica sobre los distintos puntos que menciona el «Régimen jurídico de las Administraciones públicas y Régimen estatutario de los funcionarios».

Se deduce del texto constitucional que en esta materia fue preocupación de los constituyentes la de conseguir una igualdad ante la Administración en todo el país. Este es, en parte también, en las materias a regular por la legislación básica el procedimiento

(32) BAENA del AlCÁzAR, M.: Organización..., Madrid, 1984, nota 3 de la p. 86.

(33) MORELL OCAÑA, L.: Las entidades..., cit., pp. 346-347.

(34) BAENA DEL ALCÁZAR, M.: Curso..., cit., p. 76. 
administrativo como otras de gran trascendencia en relación a los párrafos del artículo 103, como son los contratos administrativos, las concesiones y el sistema de responsabilidad civil por los daños causados.

Al ser de la competencia exclusiva del Estado las bases del régimen jurídico de las Administraciones públicas no cabe duda que, relacionado este párrafo $1 .^{\circ}$ del número 18 del artículo 149 de la Constitución, están incluidas estas medidas en los principios organizativos del artículo 103 «para todas las Administraciones públicas, y entre éstas, claro es, las Comunidades Autónomas».

Indirectamente se ha de llegar a la misma finalidad, pues si de acuerdo con el artículo $149,1,18 .^{\circ}$ se define que uen todo caso los administrados gozarán de un tratamiento común ante ellas», se está atendiendo muy expresamente a los territorios de todas las Comunidades.

Y prueba de ello eso que así se ha recogido en las leyes fundamentales de las Comunidades Autónomas en los preceptos que dedican a la actividad administrativa, quizá a falta de una legislación comunitaria.

En este sentido, verbigracia, el artículo 24 de la Ley de 21 de abril de 1983 de la Comunidad de Andalucía, dice textualmente que "la Administración de la Comunidad sirve con objetividad los intereses generales de la comunidad de acuerdo con los principios de eficacia, jerarquía, descentralización, desconcentración, coordinación y participación de acuerdo pleno a la Ley y al Derecho», en el mismo sentido la Ley de 14 de abril de 1983 , artículo $5 .^{\circ}$, de la Administración autonómica de la Comunidad canaria dice que «la Administración pública de la Comunidad canaria se organiza y actúa conforme a los criterios de eficacia, armonía, jerarquía, descentralización, desconcentración y coordinación en sometimiento pleno a la Ley y al Derecho». Principios que, más explícita y concretamente desarrolla en los siguientes artículos 54 y 55.

El artículo 37 del título $4 .{ }^{\circ}$ de la Ley de Gobierno y Administración de la Comunidad de Madrid, de 13 de diciembre de 1983 , indica al respecto que "la Administración de la Comunidad de Madrid constituida por los órganos jerárquicamente ordenados actúa para el cumplimiento de los fines con personalidad jurídica propia»; y el párrafo 2 del mismo artículo que "la actuación al servicio de los intereses generales de la Comunidad de Madrid se atiene a los principios de objetividad, publicidad, celeridad, eficacia, armonía, descentralización, concentración, coordinación y participación, con sometimiento a la Ley y al Derecho, de acuerdo con el artículo 103 de la Constitución». 
$Y$ esto, en consideración de la tesis últimamente propuesta explica que la Ley desarrolla la estructura de la Administración pública de la Comunidad de Madrid, de acuerdo con los principios que recoge la Constitución española, en particular el artículo 149, 1, 18. ${ }^{\text {. }}$.

$Y$ en el mismo sentido el articulado de la Ley de 22 de junio de 1984 «Del Presidente, de la Diputación Foral y de la Administración de la Comunidad Autónoma de Aragón» dice que «la Administración de la Comunidad, en relación a funciones y régimen jurídico de sus actos se ajustará a la regulación del Estado», y el artículo 29 de la misma que ula Administración de la Comunidad, constituida por órganos jerárquicamente ordenados $y$ dependientes de la Diputación tienen personalidad propia y ajustará su actividad a los principios establecidos en el artículo 103, 1, de la Constitución»; precepto que, finalmente, se repite en el artículo 5 de la Ley de 22 de febrero de 1983, regulación de la Xunta y del Presidente de la Comunidad Autónoma Gallega al decir que «la Xunta se reúne en Consello, que someterá su funcionamiento a los principios de unidad, colegialidad, participación y coordinación».

\section{LA ORGANIZACION Y ACTIVIDAD DE LA COMUNIDAD AUTONOMA DE CASTILLA Y LEON}

\section{La organización}

\section{A) LAS CORTES}

El 25 de febrero de 1982 se promulgó la Ley Orgánica $4 .^{a}$ aprobatoria por las Cortes Generales del Estatuto de Autonomía de Castilla y León, comprensivo de las provincias de Avila, Burgos, León, Palencia, Salamanca, Soria, Valladolid y Zamora (art. 3 del Estatutol, a las que ha de añadirse la provincia de Segovia, incluida en el proceso autonómico por posterior Ley Orgánica $5 .^{\circ}$ de las mismas Cortes Generales, promulgada el día 1 de marzo de 1983.

De acuerdo con el título I "Organización de la Comunidad» del referido Estatuto (art. 8.\%), las instituciones básicas de la Comunidad Autónoma castellano-leonesa son: las Cortes de Castilla y León, el Presidente de la Junta de Castilla y León y la Junta de Castilla y León.

De acuerdo con el párrafo 1 del artículo 147 de la Constitución, el Estatuto de Castilla y León, cual en las demás Comunidades Autónomas, "será la norma básica de cada Comunidad Autónoma y el Estado los reconocerá y amparará como parte integrante de su ordenamiento jurídicon. 
Las Cortes de Castilla y León, de acuerdo con el párrafo 1 del artículo 9 del Estatuto, representan al pueblo castellano-leonés y ejercen en su nombre, con arreglo a la Constitución y al presente Estatuto, los poderes y atribuciones que le corresponden.

De acuerdo con el siguiente artículo 10 los miembros de las Cortes de Castilla y León reciben la denominación tradicional de Procuradores y serán elegidos por sufragio universal; libre, igual, directo y secreto mediante un sistema de representación proporcional que asigne, además, la representación de las diversas zonas del territorio.

Es circunscripción electoral la provincia, asignándose a cada una de ellas un número de tres Procuradores mínimo y uno más por cada 45.000 habitantes, o fracción superior a 22.500 .

Por resolución de esas Cortes, de 16 de febrero de 1984, se promulgó el Reglamento de las Cortes Generales que desarrolla y aclara los correspondientes preceptos del Estatuto castellanoleonés.

Los capítulos I, II, III, IV y V del título I del referido Reglamento (arts. 1 a 19) y el título II del mismo (arts. 20 al 26) referentes al "Estatuto de los Procuradores» y "de los grupos parlamentarios», respectivamente, preceptúan, a nuestros efectos, que los Procuradores electos adquirirán la condición plena de Procurador, que tendrán derecho a voz y voto en las sesiones del Pleno y de las Comisiones, y el derecho a formar parte de una Comisión.

De otra parte, de acuerdo con los artículos 8 y 9, los Procuradores tendrán derecho a las dietas que se fijen en el ejercicio de su cargo, a los derechos y ayudas e indemnizaciones por los gastos que sean indispensables en el ejercicio de su cargo y a los de legalidad de la Seguridad Social siempre que tengan dedicación plena a las Cortes.

En el capítulo III mencionado, el título de "Las prerrogativas parlamentarias» se dispone (arts. 10, 11 y 12) que los Procuradores gozarán, aun después de haber terminado su mandato, de inviolabilidad por las opiniones manifestadas y por los votos emitidos en el ejercicio de su cargo y que gozarán de inmu nidad (es decir, de acuerdo con el párrafo $3 .^{\circ}$ del art. 2 al quese remite el Reglamento, que no podrán ser detenidos ni retenidos por presuntos actos delictivos cometidos en el territorio de la Comunidad, salvo en el caso de flagrante delito).

Por otra parte, de acuerdo con el capítulo IV mencionado y bajo el epígrafe "De los deberes de los Procuradores» se dispone la obligación de los mismos a asistir a las sesiones de que formen parte, a mantener el orden, la cortesía y la disciplina parlamentaria, el no utilizar o hacer uso de su condición de Parlamentarios para el 
ejercicio de funciones materiales o industriales y su obligación de efectuar declaración notarial de sus bienes patrimoniales (arts. 13 al 16).

De acuerdo con el referido capítulo $V$ del título $I$, y bajo el epígrafe «De la condición y pérdida de la condición de los Procuradores de las Cortes de Castilla y Leónı quedarán suspendidos en los derechos y deberes parlamentarios en los casos que así proceda, por aplicación de los mismos de la disciplina parlamentaria, y que perderán su condición de Procuradores por las causas de:

a) Decisión judicial que anule su elección o nombramiento.

b) Por fallecimiento o incapacidad del mismo declarada por sentencia firme judicial.

c) Por extinción del mandato al terminar su plazo.

d) Por renuncia del mismo presentada a la Mesa de las Cortes.

En el título II del Reglamento, y bajo el epígrafe «De los grupos parlamentarios», se dispone que los Procuradores en número no inferior a 5 podrán formar un grupo parlamentario, así como los que hayan sido elegidos sin pertenecer a ninguna formación política.

Los grupos parlamentarios, con su portavoz, se constituirán dentro de los quince días siguientes a la constitución de las Cortes, ningún Procurador podrá formar parte de más de un grupo parlamentario, y que ningún Procurador perderá su condición por el hecho de dejar de pertenecer a un grupo parlamentario, y el que todos los grupos parlamentarios gozarán de los mismos derechos (arts. 20 al 26).

De acuerdo con el artículo 12, 1 del Estatuto de las Cortes, serán órganos de las mismas, un Presidente, una Mesa y una Diputación permanente. Dichas Cortes funcionarán en pleno y en Comisiones (párr. 2 del mismo artículo) y se reunirán en sesiones ordinarias y extraordinarias, en períodos que comprenderán ciento veinte dias al año, entre septiembre y diciembre en el primer período, y entre febrero y junio en el segundo período, según el párrafo $5 .^{\circ}$ del mismo artículo.

Desarrollando este precepto el Reglamento de las Cortes, en su título III, y bajo el epígrafe "De la Organización de las Cortes», dispone «la Mesa es el órgano rector de las Cortes y ostentará la representación colegiada», que la Mesa estará compuesta por el Presidente de las Cortes, dos Vicepresidentes y dos Secretarios. El Presidente de las Cortes ostenta la representación de la Cámara, regula la buena marcha de los trabajos, dirige los debates y orden de los mismos y ordena los pagos, sin perjuicio de la delegación que le corresponda, teniendo en cuenta en todo caso dedicación exclusiva, de acuerdo con los artículos 27,29 y 32 del mismo. 
Los Vicepresidentes, por su orden, sustituyen al Presidente, ejerciendo sus funciones en caso de vacante, ausencia o imposibilidad de aquél siendo, asimismo, los Secretarios supervisores y fedatarios de las actas de las sesiones plenarias de la Mesa y de los grupos de Procuradores (arts. 30 y 31 del mismo Reglamento).

La elección de los miembros de la Mesa será hecha por el pleno, por medio de papeletas que los Procuradores depositarán ante el Presidente de la Mesa.

Para la elección del Presidente de la Mesa cada Procurador escribirá el nombre en la papeleta, resultando elegido el que obtenga la mayoría absoluta de los miembros, de acuerdo con los artículos 34 y 35 del mismo Reglamento.

Como ya se ha indicado, las Cortes funcionarán en Pleno y en Comisiones. El Pleno será convocado por el Presidente de las Cortes o a solicitud de al menos dos grupos parlamentarios o de una quinta parte de los miembros Procuradores en las Cortes.

Son Comisiones permanentes de las Cortes (art. 46): 1) El Estatuto; 2) Gobierno interior y Administración territorial; 3) Economía y Hacienda y Comercio; 4) Agricultura, Ganadería y Montes; 5) Educación y Cultura; 6) Bienestar Social; 7) Industria y Energía; 8) Obras Públicas y Ordenación del Territorio; 9) Presidencia; 10) Transportes, Turismo y Comunicaciones, así como las que deban constituirse por disposición legal y las de Reglamento y Procuradores (art. 4).

En el mismo sentido, y de acuerdo con el artículo 49, el Pleno de las Cortes, a propuesta de la Mesa, oída la Comisión de procuradores, podrá acordar la creación de las Comisiones que tengan carácter de fundamentales, dentro de la legislatura en que el acuerdo se adopte.

Las Comisiones no permanentes se regulan en el artículo 50 y ss., y son las que se crean para un trabajo determinado y se extinguen al final del plazo encomendado.

La elección de los Senadores que representan a la Comunidad en el Senado, que prevé el artículo 69.1,2 y 5 de la Constitución (cuatro por provincia, otro por la Comunidad y otro por cada millón de habitantes de la misma), corresponde a las Cortes, de acuerdo con el párrafo $5 .^{\circ}$ del artículo 13 del Estatuto. La Mesa de las Cortes, de acuerdo con la Junta de Procuradores, determina el número de Senadores que corresponde a cada grupo parlamentario, tal como indica el artículo 161 de la Ley.

Corroborando la preceptiva del párrafo $5 .^{\circ}$ del artículo 12 del Estatuto, los artículos 66 y ss. del Reglamento establecen que las sesiones de las Cortes serán ordinarias y extraordinarias. 
Las ordinarias comprenderán ciento veinte días al año y se celebrarán entre septiembre y diciembre el primer período, y entre febrero y junio el segundo período. Fuera de los períodos señalados sólo podrán celebrarse sesiones extraordinarias a petición de la Junta, de la Diputación permanente o de una quinta parte de los Procuradores.

Las sesiones del Pleno, de acuerdo con el artículo 68, serán públicas, salvo en los casos de: a) que se trate de cuestiones relativas al decoro de las Cortes o sus miembros o de la separación de un Procurador; b) cuando se discutan proyectos, dictámenes o informes elaborados en el seno de lás Comisiones, y c) cuando lo apruebe la mayoría absoluta de los miembros.

Las sesiones de las Comisiones, empero, y de acuerdo con el artículo 69, no serán públicas y serán secretas cuando lo aprueben la mayoría absoluta de sus miembros, a iniciativa de la Mesa, de la Junta de Castilla y León o de un grupo parlamentario o de la quinta parte de los Procuradores.

De las sesiones del Pleno y de las Comisiones se levantará acta, que contendrá una relación sucinta de las cuestiones debatidas, personas asistentes y acuerdos adoptados.

Finalmente, son órganos de las Cortes la Junta de Portavoces y la Diputación permanente.

La primera la constituyen los portavoces de los grupos parlamentarios, que se reunirán bajo la presidencia del Presidente de las Cortes.

La Junta de Portavoces, de acuerdo con el artículo 38 del Reglamento, se reunirá a iniciativa propia, a petición de dos grupos parlamentarios o de una quinta parte de los miembros de las Cortes. A la Junta de Portavoces aistirán el Vicepresidente, un Secretario de la Cámara y un Letrado de la misma.

La Junta de Portavoces será oída preceptivamente (art. 39):

1. Para fijar las cuestiones que hayan de debatirse, ordenar y allanar los debates y las bases de las Cortes.

2. Presidir la Comisión.

3. Fijar el mando de los miembros de cada grupo parlamentario, y

4. Ostentar los escaños en el salón de sesiones de los diferentes grupos parlamentarias.

La Diputación permanente, finalmente, regulada en el capítulo $\mathrm{V}$ del Reglamento, será presidida por el Presidente de las Cortes y estará formada, como mínimo, por el mismo número de Procuradores e idéntica distribución proporcional entre miembros de los grupos parlamentarios que el resto de las Comisiones. 
La Diputación p̄ermanente elegirả de entre sus miembros dos Vicepresidentes y dos Secretarios, de acuerdo con lo establecido para la elección de los miembros de la Mesa de las Cortes.

La Diputación permanente será reunida por el Presidente a iniciativa propia o a petición de los grupos parlamentarios o de una quinta parte de los miembros de aquélla; y ningún Procurador que sea miembro de la Junta de Castilla y León podrá serlo de la Diputación permanente.

En relación a estas Cortes castellano-leoneses, por último, hemos de decir que en cumplimiento y desarrollo de la preceptiva del Estatuto (párr. $1 .^{\circ}$ del art. 36 del mismo, «Organización, régimen y funcionamiento de las instituciones de autogobierno»; y también del mandato del párr. $4 .^{\circ}$ del art. 11 del mismo, que declara que la Ley Electoral determinará las causas de incompatibilidad o inelegibilidad de los Procuradores), las citadas Cortes han promulgado, con fecha 30 de marzo de 1987, la Ley Electoral de Castilla y León.

Esta Ley tiene por objeto, como se dice en la exposición de motivos y en su artículo 1, «regular las elecciones a las Cortes de Castilla y León, y tiene como otros preceptos básicos o esenciales las normas de la Ley Electoral de 19 de junio de 1985. Con esta Ley se regula, en su título l, los derechos de sufragio activo y pasivo y las incompatibilidades para el cargo de Procurador (todas las causas de inelegibilidad serán también de incompatibilidad, dice el art. 5 de la Ley).

La Administración electoral, objeto del título Il de la misma, tiene como órganos la Junta Electoral Central, la Junta Electoral de Castilla y León, las provinciales y las de zona, así como las Mesas electorales.

La Junta Electoral, con sede en las Cortes, como órgano permanente está compuesta de cuatro vocales, Magistrados del Tribunal Supremo de Justicia, y tres vocales Catedráticos o Profesores titulares de Derecho; los vocales elegirán, de entre los de origen judicial, al Presidente y Vicepresidente de la Junta.

Los miembros de las Juntas serán procesados sólo por delitos o faltas electorales mediante expediente incoado por la Junta Electoral Central.

Los miembros de las Juntas serán convocadas por su Presidente, de oficio o a instancia de los vocales; y la convocatoria de elecciones a las Cortes se celebrará de acuerdo con lo previsto en la legislación reguladora del régimen electoral, mediante Decreto del Presidente de la Junta.

En cumplimiento del artículo 20, ya expuesto, del Estatuto, en el que se dispone que la provincia es circunscripción electoral, se dispone en el título IV (arts. 18 y ss.) de esta Ley que cada provincia 
tendrá un número inicial de tres Procuradores y uno más por cada 45.500 habitantes o fracción superior a 22.500. El Decreto especificará el número de Procuradores que integran las Cortes y el que corresponde elegir a cada circunscripción electoral.

El título $\mathrm{V}$, bajo el epígrafe «Del procedimiento laboral», regula el procedimiento interno, concediendo la representación de las candidaturas a los partidos, las federaciones, coaliciones y agrupaciones.

Los partidos, federaciones y coaliciones que pretendan concurrir a las elecciones designarán un representante general y un suplente, mediante escrito dirigido a la Junta de Castilla y León.

Los representantes de la candidatura y sus suplentes se habrán de personar ante la respectiva Junta Provincial para aceptar su designación, necesitando esas agrupaciones de electores la firma, al menos, de un 1 por 100 de los miembros de la Mesa.

Las candidaturas presentadas, según el párrafo $3 .^{\circ}$ del artículo 27 , serán públicas en el vigésimo segundo día posterior a la convocatoria en el «Boletín Oficial de Castilla y León» y los «Boletines Oficiales» de la Provincia y de la Comunidad, siendo las Juntas Electorales Provinciales las que procederán a la proclamación de las candidaturas el vigésimo séptimo día posterior a la convocatoria.

El capítulo III de esta Ley está dedicado a la "Campaña Electoral», definiendo esa campaña como «el conjunto de actividades lícitas llevadas a cabo por los partidos, federaciones, coaliciones o agrupaciones en orden a la captación de sufragios».

La Junta de Castilla y León es la competente para esa campaña electoral que puede llevarse a cabo por todos los medios de publicación pública.

Se concede un tiempo gratuito de propaganda en los medios de comunicación de titularidad pública o en los ámbitos de programación para los partidos, federaciones y coaliciones que presenten candidaturas al menos en las dos terceras partes de las circunscripciones comprendidas en el ámbito de difusión o, en su caso, programación del medio correspondiente (art. 38).

Un modelo oficial, aprobado por las Juntas Electorales Provinciales, de las papeletas electorales correspondientes a la circunscripción en las que han de constar la denominación, siglas y símbolos del partido o federación y los nombres y apellidos de los candidatos y de los suplentes son los requisitos que la Ley exige, en su capítulo $\mathrm{V}$, relativo a «Papeletas y sobres electorales».

El voto por correo y la posibilidad de representación de los candidatos, por apoderados o interventores, completań el medio de procedimiento de las elecciones a las Cortes de Castilla y León. 
Se dispone, finalmente, también en la misma Ley, y a nuestros efectos, que las Comunidades Autónomas subvencionarán los gastos ocasionados a los partidos, federaciones, coaliciones y agrupaciones por su concurrencia a las elecciones autonómicas en cantidad que se fija en cada escaño obtenido, fijando los límites de estos gastos electorales de cada partido, federación, coalición o agrupación participante en las elecciones por los resultados que salgan de mutiplicar por 20 pesetas el número de habitantes correspondiente a la población de derecho de las circunscripciones donde presentan candidatos.

\section{B) El Presidente de la Junta de Castilla y Leon.}

El Presidente de la Junta de Castilla y León, de acuerdo con el párrafo 4 del artículo 15 del Estatuto, ostentará la suprema representación de la Comunidad y la de los servicios de la misma, presidiendo, asimismo, la Junta, dirigiendo sus acciones y coordinando las funciones de los mismos (el art. 10 del vigente texto refundido de la Ley del Gobierno y de la Administración de Castilla y León, Decreto Legislativo de 20 de julio de 1988, añade a este casi textual texto el de representar ordinariamente al Estado de la Comunidad).

El Presidente de la Junta es elegido por las Cortes de entre sus miembros y nombrado por el Rey, de acuerdo con el párrafo 1 del artículo 13 del Estatuto (en la forma prevista en el Estatuto y nombrado por el Rey, se dice en el art. 11 del vigente texto refundido citado).

La elección de este Presidente, de acuerdo con el párrafo 2 del citado artículo 15 del Estatuto, se realizará al comienzo de cada legislatura o, en caso de dimisión o fallecimiento del anterior, por mayoría absoluta en primera votación, o por mayoría simple en las sucesivas.

El Presidente de la Junta, de acuerdo con el artículo 10 del vigente texto refundido de la Ley recibirá el tratamiento de excelencia, y se le rendirán los honores que le correspondan a su cargo. Asimismo presidirá los actos que se celebren en la Comunidad,

(35) La primera Ley del Gobierno y la Ádiministración de Castilla y León fue promulgada por las Cortes con fecha 29 de julio de 1983. Con posterioridad, por Ley de 5 de julio de 1988 fue modificada parcialmente esta Ley, autorizando la disposición adicional de la misma, en aras de la unidad del Cuerpo legal, se dice en la misma, a que la Junta de Castilla y León refundiera en un solo texto las disposiciones legales vigentes en materia de Gobierno y de la Administración de la Comunidad, que es el Decreto legislativo 1/1988, de 21 de julio, vigente de ese Gobierno y Administración; texto publicado en el «Boletín Oficial de la Comunidad» números 142 y 175).

REVISTA DE ESTUDIOS. -11 
salvo que la Presidencia corresponda a otra autoridad superior del Estado presente en el acto.

De otra parte, el cargo de Presidente es incompatible con toda actividad profesional o mercantil y con cualquiera otra función que no derive de su condición de Procurador en Cortes, a excepción de la de Senador.

Al Presidente de la Junta le corresponden, de acuerdo con el capítulo II del título segundo del mismo texto refundido.

1) Convocar elecciones de las Cortes de Castilla y León, de acuerdo con el Estatuto de Autonomía.

2) Promulgar, en nombre del Rey, las leyes aprobadas por las Cortes, así como ordenar su publicación en el «Boletín Oficial de Castilla y León».

3) Mantener las relaciones con las demás Instituciones del Estado, así como firmar los convenios y acuerdos de cooperación con otras Comunidades Autónomas.

Asimismo le corresponderán: $1^{\prime}$ ) el dirigir y coordinar la acción del Gobierno; 2') nombrar y separar a los Consejeros de la Junta; 3') convocar, presidir y dirigir los debates y deliberaciones y suspender y levantar las sesiones de la Junta fijando el orden del día de la misma.

4) Encomendar a los miembros de la Junta el despacho de los asuntos de una Consejería en caso de vacante, ausencia o imposibilidad de su titular.

5) Designar y cesar libremente al personal eventual de su Gabinete y de los demás órganos que, en su caso, la Junta adscriba directamente a la Presidencia dentro de los créditos consignados al efecto en los presupuestos de la Comunidad.

6) Firmar los Derechos de la Junta y ordenar, en su caso, su publicación en el «Boletín Oficial de Castilla y León».

7) Velar por el cumplimiento de las decisiones de la Junta, ordenando su ejecución.

8) Recabar de los Consejeros la información acerca de su gestión.

9) Resolver los conflictos de atribuciones entre las Consejerías.

10) Nombrar los representantes de la Junta de Castilla y León en comisiones, organismos, instituciones y entidades.

11) Ejercer cualesquiera otras atribuciones previstas en la Ley.

Finalmente, en los casos de ausencia, enfermedad o impedimento del Presidente, ser sustituido por uno de los Vicepresidentes, si los hubiere, y, en otro caso, por el Consejero más antiguo, 
siendo causas del cese en sus funciones de acuerdo con el artículo 10 del vigente texto refundido:

a) La celebración de elecciones a Cortes.

b) La aprobación de una moción de censura de acuerdo con el Estatuto (36).

c) Por dimisión.

d) Por fallecimiento.

En los anteriores supuestos a), b), y c), el Presidente cesante continuará en sus funciones hasta la toma de posesión del nuevo Presidente. En el supuesto d) sería sustituido por uno de los Vicepresidentes, si los hubiere, según su orden, y, en otro caso, por el Consejero más antiguo.

C) De los Consejeros y de las Consejerías de la Junta.

De acuerdo al párrafo 2 del artículo 16 del Estatuto, una ley aprobada por las Cortes de Castilla y León regulará la composición de la Junta, cuyo número de miembros no excederá, en todo caso, de diez, además del Presidente, así como estatuto personal de sus miembros, que recibirán al nombre de Consejeros.

El repetido texto refundido vigente de 1988 dispone, en desarrollo de esa preceptiva del Estatuto, que los Consejeros son miembros de la Junta de Castilla y León y titulares de la Consejería que tuvieren asignada (art. 10).

En el artículo siguiente de ese mismo texto refundido se dispone que los Consejeros serán nombrados y separados por el Presidente de la Junta, quien se lo comunicará inmediatamente a las Cortes de Castilla y León.

Los Consejeros tienen las atribuciones de:

a) La dirección, coordinación e inspección de las Consejerías, así como las de las Entidades dependientes de la misma.

b) Preparar y presentar a la Junta los Anteproyectos de Ley y Proyecto de Decretos relativos a las Consejerías.

c) Ejercer la potestad reglamentaria y la función ejecutiva en las materias propias de su Consejería.

d) Formular el Anteproyecto de Presupuestos de la Consejería

e) El nombramiento y separacion de los cargos de su Consejería que no estén reservados a la Junta.

f) Desempeñar la Jefatura superior de su personal.

(36) El párrafo $3 \mathrm{del}$ art. 15 del Estatuto, en relación con el mismo número del art. 18, establecen que las Cortes pueden exigir la responsabilidad politica de la Junta mediante adopción por mayoría absoluta de sus miembros de la moción de censura. Esta deberá ser propuesta, al menos, por el 15 por 100 de los Procuradores y habrá de incluir un candidato a presidente de Castilla y León. 
g) La resolución de los recursos que puedan corresponderle.

h) Resolver los conflictos de atribuciones entre autoridades administrativas de su Consejería y suscitados con otras Consejerías.

i) Autorizar los gastos y pagos de conformidad con lo establecido legalmente.

j) Firmar, en nombre, de la Comunidad Autónoma, los contratos relativos a asuntos propios de su Consejería.

k) Cualesquiera otra que le sea legalmente atribuida.

En lo relativo a su estatuto personal, que regula el capítulo III del título III del texto refundido, los Consejeros tienen el tratamiento de excelencia, y le serán rendidos los honores que les corresponda por razón del cargo; asimismo percibirán la remuneración y los gastos de representación que les asignen los Presupuestos de la Comunidad, estando sujetos a las mismas incompatibilidades que el Presidente (es decir, las enumeradas en la página anterior y que señala el artículo 15 del texto refundido).

Los Consejeros tienen las atribuciones que siguen:

a) La dirección, coordinación e inspección de la Consejería, así como las de las Entidades dependientes de la misma.

b) Preparar y presentar a la Junta Anteproyectos de Leyes y Proyectos de Decretos relativos a las cuestiones propias de la Consejería.

c) Preparar el Anteproyecto de Presupuestos de la Consejería.

d) Ejercer la potestad reglamentaria y la función ejecutiva en las materias propias de la Consejería.

e) Desempeñar la Jefatura Superior del Personal de la Consejería.

f) La resolución de los recursos que puedan corresponderle:

g) Resolver los conflictos de atribuciones entre autoridades administrativas dependientes de su Consejería y suscitadas con otras Consejerías.

h) Autorizar los gastos y pagos de conformidad con lo establecido legalmente.

i) Firmar, en nombre de la Comunidad Autónoma, los contratos relativos a los asuntos propios de su Consejería.

j) Cualquier otra que pueda corresponderle.

Los Consejeros cesan en sus funciones, de acuerdo con el artículo 24 del vigente texto refundido:

1) Por cese del Presidente de la Junta, si bien continuarían en sus funciones hasta la toma de posesión de la nueva Junta.

2) Por dimisión aceptada por el Presidente de la Junta. 
3) Por revocación de su nombramiento decidida libremente por el Presidente.

4) Por fallecimiento.

En lo relativo al número de las Consejerías, las nueve establecidas por el artículo 28 de la primera Ley del Gobierno y Administración de la Comunidad de Castilla y León de julio de 1983, fueron sustituidas por un Decreto-ley de las Cortes de 7 de junio de 1985 por las de:

a) Presidencia y Administración Territorial.

b) Economía y Hacienda.

c) Agricultura, Ganadería y Montes.

d) Educación y Ciencia.

e) Bienestar Social.

f) Industria, Energía y Trabajo.

g) Obras Públicas y Ordenación del Territorio.

h) Transporte, Turismo y Comercio.

En el texto refundido vigente se establece al respecto que «La Administración de la Comunidad Autónoma se organiza departamentalmente en Consejerías», y que upor Decreto de la Presidencia de la Junta se podrian crear, modificar, suprimir o fusionar Consejerías dentro de los límites establecidos por el Estatuto de Autonomía, dando cuenta del mismo a las Cortes de Castilla y León», es decir, que desde la entrada en vigor del vigente texto refundido queda a la potestad del Presidente de la Junta (por Decreto) la creación, supresión o fusión de varias Consejerías, dando de ello cuenta a las Cortes, y dentro de los límites establecidos por el Estatuto, límites que, cual se ha dicho con anterioridad, es el de diez, además del Presidente.

Cada Consejería, de acuerdo con el mismo texto refundido vigente, se ordenará o desarrollará, en el orden central, con una Secretaría General y Direcciones Generales.

A su vez esta Secretaría General y las Direcciones Generales podrán organizarse en Servicios, Secciones y Negociados o en otras unidades orgánicas de niveles homologados.

Independientemente de ello en cada Consejería podría crearse un Gabinete con funciones de apoyo y asesoramiento del Consejero, dentro de los límites establecidos por la legislación reguladora de la Sección pública en cuanto su inclusión en el Presupuesto y al libre nombramiento de personal eventual.

Como órgano inmediatamente inferior jerárquicamente al Consejero tiene, de acuerdo con el artículo 30, las siguientes atribuciones: 1) Representar a la Consejería por orden del Consejero; 2) Actuar como órgano de comunicación con las demás Consejerias; 3 ) 
Elaborar los proyectos de planes generales de actuación de la Consejería; 4) Prestar asistencia técnica y administrativa al Consejero en asuntos que éste considere conveniente, ocupándose especialmente del control del presupuesto y de la gestión de medios materiales adscritos al funcionamiento de la Consejería, así como de los servicios generales de ésta; 5) Ejercer las demás facultades que el Consejero le delegue o la Junta desconcentrare en él, y 6) Ejercer las demás facultades y funciones que les atribuyan las disposiciones en vigor.

El Director general, por su parte, es el Jefe del Centro Directivo que tienen encomendado y detenta las atribuciones de: a) Dirigir y gestionar los servicios y resolver los asuntos de la Consejería que le corresponda; b) Vigilar y fiscalizar las dependencias a su cargo; d) Proponer al Consejero la resolución que estimare procedente en los asuntos de su competencia y cuya tramitación corresponda a la Dirección General, y e) Cualquier otro que le sea legalmente atribuidas o le delegue el Consejero.

La creación o supresión de órganos superiores al Servicio, así como cualquier variación en la denominación de atribuciones se llevará a cabo por Decreto de la Junta de Castilla y León.

Los órganos de las Consejerías de categoría inferior o igual al servicio, tanto de su esfera central como periférica, serán creados, modificados o suprimidos por el titular de la Consejería previa deliberación de la Junta; pero los dos supuestos requerirán el previo informe de la Consejería de la Presidencia y Administración territorial, con un estudio económico previo del coste de funcionamiento de la nueva organización o resultante en comparación de la anterior, $y$ el rendimiento o utilidad económica o social que pretende obtenerse de ello.

De acuerdo con el párrafo 5 de este mismo artículo 33 del texto refundido «las atribuciones de los Consejeros, salvo disposición expresa en contrario de una Ley y con el alcance que en cada caso determine por Decreto de la Junta de Castilla y León, podrán desconcentrarse en los restantes órganos de las Consejerías con categoría superior a Servicion, y las de los Consejeros, Secretarios generales y Directores generales en los Delegados territoriales.

Una vez desconcentradas las atribuciones de los Consejeros pasarán a ser propias de los órganos a los que hayan sido atribuidas y podrán, a su vez, ser delegadas; esta delegación, de acuerdo con el artículo 35, podrá hacerse a los Secretarios generales y Directores generales, excepto en los casos de: a) Los asuntos que hayan de someterse a acuerdo de la Junta; $b$ ) Los que den lugar a la adopción de disposiciones generales, y c) La resolución de recursos de alzada en los casos en que proceda. 
A su vez, las atribuciones de los Secretarios generales son delegables en los Delegados territoriales, y las de unos y otros en los Jefes de Servicio o, en su caso, de Sección, que de aquéllos directamente dependan, previa autorización del Consejero funcionalmente competente.

Estas resoluciones administrativas adoptadas por delegación se considerarán dictadas, a todos los efectos, por el órgano delegado; la revocación de la delegación podrá hacerse en cualquier momento por el órgano que la haya conferido.

No serán delegables las atribuciones que se posean por delegación y esas resoluciones delegadas se harán constar así expresamente en los actos que se dicten (art. 35 y párr. 2 del art. 36), delegaciones que habrán de publicarse en el «Boletín Oficial de Castilla y León».

En cuanto a la Administración periférica, que el mismo texto refundido regula, la Comunidad Autónoma podrá organizarse en Delegaciones territoriales de una o varias Consejerías de la Junta en cada una de las Provincias de la Región.

Esas delegaciones de la Junta o de varias Consejerías dependerán de la Consejería de la Presidencia y Administración territorial y de las Consejerías que correspondan por razón de las distintas competencias materiales. En otro caso las Delegaciones territoriales dependerán orgánica y funcionalmente de las correspondientes Consejerías.

Al frente de cada Delegación territorial habrá un Delegado territorial que tendrá las atribuciones de: 1) Ostentar la representación de la Consejería, Consejeros o Juntas de Castilla y León, según los casos, en el ámbito territorial correspondiente; 2) Desempeñar, sin perjuicio de las atribuciones de los órganos superiores, la Jefatura de personal de la Delegación; 3) Coordinar los órganos a su cargo, impulsar la actividad administrativa y velar por el eficaz empleo de los medios disponibles en el territorio de su competencia, y 5) Ejercer las demás competencias que le sean atribuidas o delegadas.

Las Delegaciones podrán organizarse en Servicios territoriales, Secciones y Negociados, o en otras unidades de niveles homologados, orgánica y funcionalmente dependientes, a través de la Delegación respectiva, de la Delegación territorial que le corresponda por razón de la materia de sus atribuciones.

Excepcionalmente la Junta podrá disponer la adscripción directa de órganos centrales de unidades periféricas cuando en su denominación o atribuciones se llevaren a cabo por Decreto de la Junta de Castilla y León. 
La creación, modificación, o supresión de los órganos de las Delegaciones territoriales de varias Consejerías requerirá orden conjunta del Consejero de la Presidencia y Administración territorial y del titular de la Consejería de la que dependan funcionalmente, previa delegación de la Junta.

Finalmente, a nuestros efectos, se dispone en el texto refundido que la creación, modificación y supresión de los órganos de las Delegaciones territoriales o de varias Consejerías requerirán orden conjunta de los Consejeros de la Presidencia y Administración territorial y del titular de la Consejería de la que dependan funcionalmente, previa deliberación de la Junta.

\section{Los principios de actividad de la Comunidad}

En la Comunidad de Castilla y León para el seguimiento de su actividad ha de tenerse en cuenta como principio básico del contenido del párrafo 2 del artículo 3 del Estatuto que establece que una ley de las Cortes de Castilla y León determinará la ubicación de los organismos de la Comunidad Autónoma, a propuesta de la Junta, ateniéndose a los criterios de centralización, eficacia, coordinación de funciones y de la tradición histórica (37).

Este precepto ha sido recogido y desarrollado por el capítulo III (arts. 37 y ss.) del vigente texto refundido de la Ley de Gobierno y la Administración territorial en los que se establece que los órganos y servicios de la Administración territorial de la Comunidad se ubicarán en la capitalidad en que tiene su sede las instituciones de autogobierno de la Región, o en los términos municipales de su entorno en caso de necesidad apreciada por la Junta.

Excepcionalmente, se dice en el artículo 38, la Junta podrá disponer la temporal o permanente ubicación de algunos de sus servicios centrales en otra ciudad cualquiera de la Región desde donde puedan atenderse con mayor proximidad, rapidez y eficacia la satisfacción de sus necesidades públicas de que se trate, por tener este carácter altamente localizado en una parte del territorio regional más inmediata a la ciudad elegida.

También se dispone en este capítulo que las Delegaciones territoriales se ubicarán en las capitales de las Provincias de la Región, sin perjuicio de que alguno de sus órganos se localice, por acuerdo de la Junta, en otros municipios de las correspondientes Provincias.

(37) Por sendas Leyes de las Cortes de 29 de diciembre de 1987 se fijó la sede de las Instituciones de autogobierno de la Comunidad en Valladolid, y la sede del Tribunal Supremo de la Comunidad en la ciudad de Burgos. 
Es, asimismo, precepto básico al respecto el párrafo 1 del artículo 19 del Estatuto, para el cual «las relaciones entre la Comunidad Autónoma y la Entidades territoriales que se formen se regirán por lo establecido en la legislación del Estado y el presente Estatuto», es decir, con respecto a la autonomía de los municipios (art. 140 de la Constitución) y el que la Provincia es una Entidad local con personalidad jurídica propia determinada por la agrupación de municipios (art. 141 de la misma).

El vigente texto refundido de 1988 establece a estos efectos de actividad que «la Administración de la Comunidad Autónoma de Castilla y León, constituida por los órganos jerárquicamente ordenados, actúa para el cumplimiento de sus fines con sometimiento pleno a la Ley y al Derecho y con personalidad jurídica de la "Comunidad Autónoma".

Y en relación a la Administración periférica que «estará sometida a los principios y normas de organización y actuación de la administración del Estado y gozará de los mismos privilegios. En ausencia de legislación específica actuará con carácter supletoria la del Estado»; principio que hace expresa referencia a los principios de actuación de la Administración pública de eficacia, jerarquia, descentralización y coordinación proclamados por el párrafo 1 del artículo 103 de la Constitución.

Muy positivamente estos mismos principios son los consagrados en el artículo $4 .^{\circ}$ del vigente texto refundido, relativo a «la Administración de la Comunidad Autónoma» y que han sido expuestos principalmente, respecto a la eficacia o utilidad de la creación de órganos, prohibición de duplicidad de los mismos, delegación de atribuciones tanto en la Administración central de la Comunidad como en la periférica, descentralización de funciones de las Consejerías y prestación de los servicios de las Delegaciones territoriales en Servicios territoriales, Secciones y Negociados.

Independientemente de ello el principio de control, estudiado por la doctrina, está expresamente incluido en los numerosos supuestos de necesidad de aprobación y en los órganos superiores sobre los inferiores y en los dictámenes que se exigen en numerosos casos para la creación de órganos. 
